\title{
La construcción de una propia matriz civilizatoria como ruta en la búsqueda del "buen vivir"
}

\section{Building a Civilising Matrix as a Way to Good Living \\ A construção de uma própria matriz civilizatória como caminho na busca do "bem viver"}

DOI: http://dx.doi.org/10.15359/siwo.7-2.4

\author{
Milton Calderón \\ yarteb@gmail.com
}

Recibido: 4 de agosto de 2013

Aprobado: 5 marzo 2014

\section{Resumen}

Dos matrices civilizatorias configuran el pensamiento y las prácticas culturales en el continente Latinoamericano: la occidental moderna, y la ancestral contemporánea, ambas en permanente construcción. Frente a ello, se requieren procesos de diálogo intercivilizatorio que se orienten hacia la denominada transmodernidad y que culminen en el acercamiento al paradigma del Buen Vivir y a la Epistemología del Sur. Este camino ha de pasar por el reconocimiento de los propios saberes y concepciones, la lucha por la consecución de objetivos comunes, la mirada planetaria, y la ciencia que apunte al desarrollo endógeno y a la complejidad.

Palabras clave: Matrices civilizatorias, diálogo, transmodernidad, epistemología del sur, Buen Vivir (Sumak Kawsay).

\begin{abstract}
Two civilizational models configure the thinking and cultural practices in Latin America: the modern Western and the ancient contemporary, both in permanent construction. Against this, are required inter civilizational dialogue processes that are directed towards the so-called transmodernity and culminate in the approaching to the "Wonder Living" paradigm and South epistemology. This route has to pass through the recognition of own knowledge and ideas, the
\end{abstract}


struggle for common goals, planetary gaze, and science that points to endogenous development and complexity.

Keywords: Civilizational models, dialogue, trans-modernity, south epistemology, Wonder Living (Sumak Kawsay).

\section{Resumo}

Duas matrizes civilizatórias configuram o pensamento e as práticas culturais no continente Latino-americano: a ocidental moderna, e a ancestral contemporânea, ambas em permanente construção. Diante disso, são necessários processos de diálogo inter-civilizatório que se orientem para a denominada trans-modernidade e que culminem na aproximação ao paradigma do "Bem Viver" e à Epistemologia do Sul. Este caminho deve passar pelo reconhecimento dos próprios saberes e concepções, a luta pela consecução de objetivos comuns, a visão planetária, e a ciência que indique o desenvolvimento endógeno e a complexidade.

Palavras chave: Matrizes civilizatórias, diálogo, trans-modernidade, epistemologia do sul, Bem Viver (Sumak Kawsay). 


\section{Siwô' Volumen 7, número 2, año 2013}

\section{Introducción}

Frente a la complejidad del mundo actual, variopinto y diverso, en el que coexisten grupos humanos heterogéneos, se hace necesario orientar la reflexión hacia la búsqueda de un auténtico pluralismo concebido como "posibilidad de que los individuos de diferentes culturas interactúen y se interpreten recíprocamente, aunque tengan diferentes concepciones del mundo" (Rescher, 1993. Citado en Argueta, 2011).

Esta necesidad se asienta aún más si se considera que cada cultura es el resultado de construcciones históricas y que las mismas no son ni puras ni completas (Krotz, 2002). El famoso concepto de Geertz, quien manifestaba que cultura es un "sistema de concepciones expresadas en formas simbólicas por medio de las cuales la gente se comunica, perpetúa y desarrolla su conocimiento sobre las actitudes hacia la vida." (Geertz, 1988:7), se presta para el cuestionamiento del que surgen algunas preguntas claves: ¿cuál es el paradigma en el que se basa el sistema de concepciones del cual se forma parte en Abya Yala, América Latina?, ¿qué formas simbólicas son utilizadas, desde tal hibridación, para la comunicación y el desarrollo del conocimiento? Y por supuesto ¿Cuál es el lugar epistemológico que orienta el actuar del sujeto en este continente?

Pues bien, siguiendo a Haverkort y otros (2013) podría considerarse que existen dos matrices civilizatorias: la occidental moderna, y la ancestral contemporánea. Se entiende ambas vistas desde el sur, no solo como espacio geográfico sino simbólico (De Sousa, 2009), y por ello, como parte integradora del sistema cultural de los pueblos latinoamericanos. Empero, si dichas matrices implican la conformación de un sistema de concepciones que se han ido desarrollando, conformando e integrando a lo largo de la historia, entonces, los mismos son actualmente incompletos. Contrario a lo que se podría pensar, dicha cualidad es significativamente positiva pues permite la creación de puentes epistemológicos que transformen concepciones respecto de la ciencia, del desarrollo y de la cultura misma.

En otras palabras, ni la matriz occidental, ni la matriz de los pueblos ancestrales están cerradas y por lo tanto, requieren de nuevos elementos que les permitan seguir construyendo su sistema simbólico. Llevar adelante esta tarea no es un asunto que deba tomarse a la ligera puesto que 
implica diálogo y como tal, requiere de argumentos que hagan posible una verdadera ética del discurso como "única vía de solución para el problema de una ética de la responsabilidad posconvencional" (Apel, Dussel y Fornet, 1992:12). Se requiere por lo tanto deconstruir (Derrida, 1997) las actuales dinámicas que orientan el pensamiento y la reflexión latinoamericana para, desde allí, establecer nuevos paradigmas, coherentes con la lucha y la necesidad de salir definitivamente de los actuales “estados coloniales" (De Sousa, 2009). Tal dinámica bien puede recordar al profeta Jeremías a quien le fue dirigido el oráculo otorgándole autoridad "para arrancar y arrasar, destruir y demoler, edificar y plantar” (Jr. 1, 10).

Ahora bien, para desarrollar una visión endógena como paradigma científico en el sentido manifestado por Kuhn (1962), es decir como "una visión del mundo coherente, con modelos, teorías, valores, supuestos y métodos compartidos por la comunidad científica" (Haverkort et al., 2013:37), es necesario abordar las mencionadas matrices civilizatorias existentes y sus respectivas características. Desde allí se podría intentar hacer una síntesis de las mismas como una tercera alternativa que sea producto del diálogo de los saberes y la revalorización de las ideas propias de la Patria Grande.

\section{La matriz occidental moderna y eurocéntrica}

Si bien los países del continente latinoamericano han pasado por procesos de independencia, que en algunos casos han sido duraderos y han costado la vida de muchas y muchos, eso no significa que haya habido una auténtica liberación cultural, razón por la cual, en varias de las costumbres y formas de pensar, hay signos de fuerte alienación. Es la lógica de la monocultura del saber según la cual "todo lo que el canon no legitima o reconoce es declarado inexistente" (De Sousa, 2009), determinando de esta manera el consecuente epistemicidio.

En general, tales situaciones legitiman el estado de colonialidad en la que aún los pueblos del sur se encuentran atados y lamentablemente aletargados, y esto, si bien tiene mucho que ver con el continente europeo, es el resultado de múltiples causas aparecidas a lo largo de la historia.

Un punto de partida importante en este análisis es el relacionado a la auto-representación europea de considerarse como "centro de la historia y del mundo", afirmación que no es más que una pretensión, ya que desde el principio no ha cumplido con dicha característica, "ni siquiera con el 


\section{Siwô’' Volumen 7, número 2, año 2013}

imperio romano (que por su ubicación extremadamente occidental nunca fue centro ni siquiera de la historia del continente euro-afro-asiático)" (Dussel, 2000:43).

Cabría entonces la válida pregunta ¿Por qué si Europa no ha sido centro de la historia, es considerada como tal, e incluso transmitida así en el mundo académico?

Un acercamiento a la respuesta puede hallarse en el concepto de "eurocentrismo", producto de la modernidad, como categoría abstracta que hace referencia a un sistema efectivamente surgido en Europa y que se legitima a través de los procesos de conquista, dominación y colonización que se desarrollaron a partir de 1492. Considerando, como se ha venido manifestando, que aún existe un estado colonial, es posible que se tienda a aplicar dicha categoría, válida solo para un después de dicha fecha, a un antes de la conquista, asumiendo que la historia latinoamericana y por lo tanto, el horizonte social, económico, político y cultural del continente se hallaba en Europa, aún antes del periodo en mención. Por lo tanto, decir Europa no es decir eurocentrismo, puesto que, por un lado, la "Europa Moderna" que hoy conocemos no es la "Europa primera", y por otro, en los siglos anteriores a la conquista "no hay fácticamente historia mundial (sino historias de ecúmenes yuxtapuestas y aisladas: la romana, persa, de los reinos hindúes, del Siam, de la China, del mundo mesoamericano o inca en América, etc.)" (Dussel, 2000: 44).

El eurocentrismo posterior a los períodos de conquistas y explícito colonialismo, se basa sobre todo en el llamado "mito" de la modernidad que justifica una praxis irracional de violencia llevada a cabo precisamente desde Europa. Tal expresión de barbarie, maquillada de desarrollo, sugiere además otro camino para entender la marginalidad y dominación que ha afectado todo un siempre a América Latina, y que además ha carecido, a nivel general, de una auténtica criticidad.

Siguiendo nuevamente a Dussel (2000), el mito de la modernidad podría describirse así:

1. La civilización moderna se autocomprende como más desarrollada y superior.

2. La superioridad obliga a buscar el desarrollo de los más primitivos, como un imperativo moral.

3. Dicho imperativo se ejecuta desde la educación a la europea, por lo que se entenderán desde este punto de vista conceptos como "desarrollo". 


\section{Siwô' Volumen 7, número 2, año 2013}

4. Como hay oposición a este proceso "civilizatorio", hay una violencia justificada, para alcanzar la dicha "modernización".

5. La dominación produce víctimas que son consideradas como sacrificios para la salvación moderna, y por ello hay un héroe civilizador y unos bárbaros sacrificados.

6. Para el moderno, el culpable es la víctima por oponerse al proceso de civilización.

7. Por este carácter civilizatorio, los sufrimientos y sacrificios son inevitables.

Ahora bien, en base a esta construcción que permite y justifica la dominación europea de los pueblos de Abya Yala, para que entren en su "modernidad", se han establecido, a lo largo de las épocas históricas, diferentes formas de gestión consecuentes con tal ideal. Un primer momento hace relación a los periodos históricos denominados como tal: colonia. Otros varios, responden a nuevos modelos de dependencia que hacen patente aún el mito de la Modernidad, ahora ampliado y relacionado a nuevas formas de explotación.

Uno de estos modelos fue el liberalismo, que exigía "una transformación de todas las estructuras, para que la libertad ilimitada del orden espontáneo sea vivible para todos y a la luz del día" (Hinkelammert, 1988:84). Las consecuencias a nivel político, económico, social y cultural en América Latina saltan a la vista en el momento en que, en virtud de tal discurso de la libertad, se promovió la privatización de dichas esferas, ahondando la alienación, aniquilando las características propias, y orientando a la sociedad, desde tal modernidad a la europea.

En base a los mismos presupuestos surge posteriormente el comunismo cuya intención fue abolir el Estado pero de un modo planificado. El fracaso en tal intención, tanto desde el mercado (liberalismo) como desde la planificación, hizo visible la voluntad de poder (Nietzsche, 2006), que llegado el momento justificó el uso de la violencia. Surge de este modo el anti-racionalismo del fascismo-nacismo que parte de la idea generalizada que "solamente el Estado puede hacer desaparecer o marginar al Estado y que, por lo tanto, la abolición anti-estatista de este presupone una concentración de todos los poderes en el Estado" (Hinkelammert, 1988:88), presupuesto que hace nacer además otro modelo de gestión del mito moderno llamado Estado Totalitario.

La post-modernidad, que presupone la superación del racionalismo, y del cual surge el neoliberalismo que es de hecho anti-racionalista y "se niega al reconocimiento de una ética 
universal de derechos humanos derivada de la razón" (Hinkelammert, 1988:94), ahonda las consecuencias injustas haciendo de América Latina uno de los continentes más pobres a pesar de la riqueza de sus recursos. A lado de estos modelos surgidos en el corazón de la modernidad van apareciendo procesos de afianzamiento correspondientes a dicha mirada alienante, tales como la globalización, la revolución informática y el desarrollo tecnológico, la unipolaridad política y la crisis ecológica (Delgado y Escobar, 2006).

Metafóricamente, la política agraria de José narrada en el Antiguo Testamento (Génesis 47) podría compararse muy bien con estos afanes "modernistas" y "desarrollistas" venidos desde occidente y cuyo fin es en realidad la dominación de los pueblos. Tal episodio, surgido en las entrañas del poder, manifiesta todo un proceso de expropiación en el que se les quita: primero, el dinero que poseen y la capacidad de seguirlo adquiriendo; luego el alimento (sus ovejas y vacas) y todo aquello que puede proporcionárselos como sus burros y caballos, instrumentos de producción; luego la tierra y la vida; y como si no fuera suficiente, la libertad y la conciencia, razón por la cual se aniquila toda capacidad crítica y de lucha, y que se expresa muy bien, cuando después de que se les ha quitado todo, manifiestan al Faraón "Nos has salvado la vida" (Gn. 47, 25). (Gallazi, 1995).

\section{La matriz ancestral contemporánea y contextual}

Partiendo de la afirmación de la existencia de culturas diversas, endógenas, y de historias particulares que forman el corpus identitario de los pueblos, puede manifestarse que hay otros modos de concebir la historia que, por los mecanismos de poder, son invisibilizados, pero que existen y están presentes a lo largo del mundo, y del continente. Pueblos que forman la categoría simbólica de "sur" siguiendo a De Sousa (2009) y que han sido atacados y aplastados culturalmente aunque muchas veces de modo sutil.

Es notable tal situación, por ejemplo, en el uso que se hace del poder para alterar el lenguaje de algunos pueblos ancestrales, lo cual ha hecho que palabras kichwas como "longo" o "runa" se consideren despectivas, verdaderos insultos, arrancándoles su profundo significado: "joven" y "ser humano", y garantizando de esta manera el anquilosamiento de la cultura originaria. Puede verse también tal aplastamiento en las fiestas que, poco a poco, fueron tornándose cada vez más 


\section{Siwô' Volumen 7, número 2, año 2013}

religiosas, militares, occidentales, en detrimento de lo propiamente andino, indígena y endógeno. De esta manera cuando los indígenas van a recordar a sus difuntos en su día, lo hacen con la clara intromisión de un elemento ajeno a tal cosmovisión inicial, viviendo de esta manera un rito vinculado a la tierra y a los seres queridos que han dejado de existir, pero al mismo tiempo, con ritualismos litúrgicos traídos desde una Iglesia claramente occidental, y por ello, parte de la primera matriz aquí presentada. Ello hace recordar las famosas palabras de Desmond Tutu: "Vinieron. Ellos tenían la Biblia y nosotros teníamos la tierra. Y nos dijeron: "Cierren los ojos y recen". Y cuando abrimos los ojos, ellos tenían la tierra y nosotros teníamos la Biblia" (Galeano, 1992).

Es en este sentido, de la historia y el pensamiento contextualizado desde los pueblos ancestrales, que se puede hablar de una matriz alternativa y diferente. Abya Yala es el nombre que en la actualidad muchas organizaciones, Estados, gobiernos, visiones de la Modernidad alternativa le dan al continente Latinoamericano, y que significa "tierra de sangre viva", "tierra en florecimiento". Esta Abya Yala posee una historia importante que merece ser revalorizada en tanto se trata de una verdadera civilización con su propia matriz en permanente construcción, capaz de mirar el mundo desde una perspectiva propia y distinta, en base a una cosmovisión (perspectiva de los pueblos ancestrales), en contraposición a la cosmología (perspectiva cartesiana europea).

Por supuesto, tomar como punto de partida a Abya Yala, no significa que otros pueblos de África o Asia, o cualquier parte del mundo estén ahora excluidos de poseer sus propias matrices. El principio del que se parte es que hay una verdadera civilización en los pueblos originarios y que por lo tanto existen "ontologías y epistemologías que organizan a sus sociedades de una manera totalizadora y no fragmentada" (Haverkort el al, 2013:26).

Ahora bien, si se parte de que la modernidad como tal, designa la contemporaneidad de una época en el momento de su clasificación, pero en "términos de una temporalidad cualitativamente nueva, que se trasciende a sí misma y que tiene el efecto simultáneo de distanciar el presente hasta del pasado más reciente, que es así identificado" (Payne, 2008:476), podría decirse que los pueblos originarios, así como cualquiera de la humanidad, han estado siempre en un estado de "Modernidad". Surge así un nuevo significado de la categoría que moderniza lo histórico (puesto 


\section{Siwô’' Volumen 7, número 2, año 2013}

que en su momento fue presente), y al mismo tiempo permite darle fuerza a lo contemporáneo y por lo tanto auténticamente moderno, desde el contexto propio de dichos pueblos.

Desde esta perspectiva la "Modernidad eurocéntrica" no es la misma de los pueblos ancestrales, los cuales pueden establecer distintos periodos históricos, incluso desde otro tipo de categorías. Claro está que desde la visión hegemónica, hay un momento en el que América Latina ingresa a formar parte de la historia y ese sería el momento de la conquista. La expresión "entrar en la Modernidad" ha de ser entendida entonces como un estado de "civilizarse" gradualmente, pasando de la barbarie a una mejor forma de vida. Se percibe cómo en ello juega un importante papel la historia como espacio de transmisión de los sustentos de la colonialidad.

La historia tal como se viene contando (volviendo al mito de la Modernidad) permite garantizar la alienación social, cultural, económica, epistémica de los pueblos de modo que sea posible mantener el status quo. No es lo mismo contar el pasado desde el punto de vista del poder, que contarlo desde el punto de vista de quienes fueron los protagonistas de las múltiples resistencias históricas a lo largo de los años. Muchas veces la historia real y concreta que se oculta y achica bajo el término de pre-historia -como si no importara para la identidad adquirida y a veces también escondida- es la que marca el camino de lo que se es en la actualidad. Como bien expresa Galeano (2004:31): "Desde el punto de vista de los indios de las Islas del Mar Caribe, Cristóbal Colón, con su sombrero de plumas y su capa de terciopelo rojo, era un papagayo de dimensiones jamás vistas".

Los textos bíblicos también aportan de un modo interesante a esta constante lucha de visiones, en las que lamentablemente ha sido la visión hegemónica la que generalmente ha triunfado. Con ello se puede además percibir cómo las matrices civilizatorias se hacen presentes en las profundidades de los relatos del originario pueblo de Israel, siempre en lucha por hacer que su visión sea considerada respecto de la establecida constantemente por quienes ejercían el poder. Tal es el caso de los relatos sobre los mandamientos en los que puede verse claramente una perspectiva ancestral, contextualizada, comunitaria, profética e igualitaria (Dt. 5, y Ex. 20) y paralelamente una dominante, injusta, corrupta, expropiatoria, que bien podría decirse capitalista (Ex. 34). 


\section{Siwô’' Volumen 7, número 2, año 2013}

\subsection{El diálogo como elemento indispensable en la construcción de una matriz civilizatoria endógena}

Frente a la "Modernidad", se hace necesario afirmar la existencia de otra modernidad, que parta de la resistencia de los pueblos invisibilizados. Nada más manifestar con Dussel (2000:48), que "el 'eurocentrismo' de la Modernidad es exactamente el haber confundido la universalidad abstracta con la mundialidad concreta hegemonizada por Europa como centro". Por ello ante la existencia del colonialismo y del saber endógeno latente se hace sumamente importante el diálogo. Solo así se podrá continuar en la construcción de una propia matriz.

No se trata tampoco de cualquier conversación espontánea, sino de un genuino diálogo ético que se sobreponga a la imposición cultural. Para ello, se hacen necesarios algunos presupuestos definidos también desde un propio paradigma:

1. El diálogo desde Abya Yala merece una adecuada "ecología de saberes" (De Sousa, 2009) que tome como presupuesto ético, la consecución de una justicia cognitiva global. Este tipo de justicia pasa por el reconocimiento de las cosmovisiones y saberes que posee el mundo indígena y que de una u otra manera configuran el horizonte de sentido del cual se forma parte en el continente.

2. El diálogo cultural y el reconocimiento pasa por considerar los saberes como verdadera ciencia, y las concepciones de vida como verdadero desarrollo, lo cual requiere la globalización de algunas ideas como por ejemplo las referidas al cuidado de la Tierra que permita "disfrutar de las bondades de la Pacha Mama". ${ }^{1}$ Frente a la sobreexplotación de los recursos y la ética global. Esto es algo no negociable.

3. Así como ha habido aplastamiento cultural, es importante que haya procesos de devolución de elementos simbólicos. El reconocimiento no se puede dar solamente a nivel de los saberes, puesto que el mismo requiere nuevas miradas históricas e incluso la recuperación de espacios propios y significativos. Solo así se podría hablar de una auténtica reivindicación.

\footnotetext{
${ }^{1}$ Expresión utilizada en el mundo Andino para referirse a la Tierra de la cual formamos parte.
} 
4. No hay diálogo posible si no se considera el contexto. Los procesos de configuración cultural pueden desarrollarse mediante el diálogo de saberes y metodologías coherentes con la intencionalidad revalorizadora de una matriz endógena. La matriz contemporánea ancestral es necesariamente contextual, y por ello debe tocar también campos como el científico y el relacionado a la investigación.

\subsection{La transculturalidad resultante de los procesos dialógicos}

Se tiene entonces dos paradigmas diferentes de "Modernidad": uno eurocéntrico, y otro desde el horizonte mundial. El primero pasa por un "llegar a ser como Europa, que es central en la historia", y el segundo por la consideración de que todo proceso histórico es de por sí, moderno. En esta segunda visión se hacen patentes por un lado la emancipación, y por otro la mítica cultura de la violencia civilizatoria (primera matriz), y solo en él se puede hacer visible al otro minimizado, ocultado y excluido por la mirada occidental eurocéntrica. Solo desde allí es posible entonces la alteridad (Levinas, 1993) y el diálogo cultural de las múltiples civilizaciones que como centro permiten lo que Dussel (2000) denomina la Transmodernidad.

Es importante partir de una condición indispensable y es el reconocimiento de los aportes de las diferentes civilizaciones en los distintos campos de vida. Ello si bien es cada vez más complejo por los procesos materiales y culturales de globalización, se hace necesario en la medida en que toma como punto de partida la aceptación de los procesos históricos de los "otros" como legítimos. Un ejemplo en este sentido es la lucha Waorani, que se lleva a cabo en el territorio ecuatoriano y cuyo trasfondo es la separación de las familias al momento en que la civilización occidental ingresó con las petroleras y les comenzó a mostrar las bondades de "ser como nosotros". Dos grupos se separaron de los demás rechazando de esta manera cualquier intento de "desarrollo", y optando voluntariamente por el no contacto con la civilización occidental. Desde el punto de vista de la matriz occidental, ellos son "no contactados", desde su punto de vista, lo somos nosotros. La transculturalidad, en el ejemplo, es el anhelo de los pueblos de seguir viviendo de acuerdo a sus presupuestos de vida, tradiciones, arte, epistemología, cosmovisión, y no de acuerdo a presupuestos venidos desde afuera, y muchas veces por imposición. Transculturalidad que solo es posible desde un diálogo oportuno y adecuado entre matrices, denominado por ello inter-civilizatorio. 


\section{Siwô’’ Volumen 7, número 2, año 2013}

A partir de este diálogo, por ejemplo a nivel económico, podrían aprovecharse las visiones comunitarias de las economías de los pueblos que existen en el continente y que buscan el equilibrio y la justicia global desde su propio modelo de desarrollo denominado generalmente "Buen Vivir". En palabras de Haverkort (2013:28):

El mercado, la competitividad y la calidad por sí mismas no generan desigualdades sociales y económicas, o instauran un sistema de explotación humana, sino más bien la forma en la que es reapropiada la riqueza generada y la propiedad sobre esos medios de producción. En ese marco, las economías de reciprocidad y redistribución presentes en las civilizaciones y pueblos originarios no niegan ni son negadas por el mercado mundial, más bien aportan a éste en una suerte de valoración social y simbólica, no solo económica de los bienes producidos, porque de lo que se trata es de redistribuir y no de acumular.

Otro punto importante en que el diálogo puede hacerse significativo a nivel inter-civilizatorio es en el manejo del poder, ya que como bien se ha abordado en la primera parte, la búsqueda de la "libertad", que además posibilite la eliminación del Estado, culmina generalmente en nuevos Estados Totalitarios. La visión de la democracia como participación desde la comunidad en función de los contextos puede ser una excelente alternativa para que se recree esta dinámica que, por vulnerada, es actualmente poco valorada.

Finalmente la civilización andina y otras de los pueblos originarios, pueden ser una fuerza en las relaciones ecológicas en tanto parten de un principio de reciprocidad que considera que no se debe sobreexplotar o contaminar los recursos naturales para la generación de riqueza y de capital, sino para la supervivencia, y la satisfacción de las necesidades, y por lo tanto, en menor dimensión que en el modelo capitalista.

Todo esto puede sintetizarse en una visión de crecimiento intensivo, centrado en el desarrollo de las comunidades e individuos, contrario al extensivo centrado en la conquista, la colonización y el consumo. Podría hablarse más bien de conexión, comunicación y consciencia (Lazlo, 2007) que permitan una verdadera revolución de la vida y de la sociedad y lancen a las personas a la lucha por un mundo más hermano y más humano. 


\section{Siwô' Volumen 7, número 2, año 2013}

Sin duda el diálogo es un reto que pasa por la valorización de la civilización de la cual se forma parte y de la construcción de una utopía que surja de la emancipación y la lucha, pues como expresa Hinkelammert (1988:101) "hay que reenfocar la utopía como lo absolutamente imposible que, por su misma imposibilidad, puede inspirar todas las posibilidades". Solo con la mirada utópica y transformada, se puede ser consciente de la necesidad de enfrentar los peligros y tomar decisiones para vivir y actuar responsablemente con un sentido de compromiso hacia los demás y hacia el futuro compartido (Lazlo, 2007).

Ese ideal implica la construcción de todo un mundo de vida, donde el objetivo no sea el lucro por el lucro, sino la satisfacción de las necesidades; donde exista una clara conciencia de que el poder se encuentra en quienes lo otorgan, es decir el pueblo; donde no haya clases, ni discriminación, ni explotación; donde la sociedad participe de las decisiones tomadas; y donde, además, se promueva el respeto a la vida y a la naturaleza en la que estamos incluidos nosotros como seres humanos. Se trata de la posibilidad real de Vivir Bien, el Sumak Kawsay.

El reconocimiento, la reivindicación y la revalorización de los elementos originarios de la cultura propia, permitirá, por un lado, la consciencia de los elementos simbólicos que conforman el mundo de vida en Abya Yala, y por otro, la postura crítica necesaria para entender que nada de lo que se posea de occidentales tiene sentido si no pasa primero por una matriz surgida en las entrañas de la historia de los pueblos. En ello el pueblo de Israel nuevamente ofrece una lección: cuando se preguntaron y quisieron emprender el camino de recuperación de su identidad perdida con la esclavitud, encontraron una respuesta muy sabia, había que buscar tal identidad dentro de su propio caminar, en los orígenes, en la historia. Y de esa convicción surgen los primeros textos bíblicos (Gallazi, 1995).

\section{Epistemología del sur y buen vivir: alternativas y aportes matriciales}

Si se hace una revisión de la historia académica personal es muy probable que se encuentren categorías que no se pueden aplicar tal como fueron transmitidas en el contexto de vida, es decir desde los pueblos latinoamericanos. Ejemplos de esto pueden ser el concepto de "propiedad" contrastado con el de "propiedad comunal"; el de "ciencia" contrastado con el de "sabiduría", o el de "desarrollo" contrastado con el "vivir bien" o "buen vivir". Por lo tanto, al hacer una lectura 


\section{Siwô' Volumen 7, número 2, año 2013}

de la sociedad, cultura, economía, política, ideología latinoamericanas se suele utilizar categorías venidas de afuera, llegando en muchas ocasiones, a conclusiones sesgadas y poco acertadas. El cambio paradigmático como aporte a la matriz civilizatoria ancestral contemporánea y contextualizada puede nutrirse de lo que De Sousa (2009) denomina "epistemología del sur".

No basta con aprender a mirarse desde dentro, puesto que tal como se lo ha expresado, se viene arrastrando una gran cantidad de precomprensiones, que configuran ya un particular mundo de sentido (Heidegger, 2007), epistemológicamente eurocéntrico. Se hace necesario entonces, hacer una opción por un lugar epistemológico, y además aprender a utilizar las categorías aprendidas para elaborar nuevas miradas, esto es, hacer uso contrahegemónico de instrumentos hegemónicos, de modo que la propiedad comunitaria sea, desde esta perspectiva, verdadera "propiedad", los saberes, ancestrales y presentes, verdadera "ciencia", y los propios horizontes del Sumak Kawsay verdadero "desarrollo". De esta manera, se valora la contribución de la ciencia occidental moderna de origen eurocéntrico pero se la utiliza para contrarrestar la injusticia que la misma hace a las culturas y sistemas de conocimientos locales del mundo (Haverkort et al, 2013).

Gran aporte a esta intención es lo que los pueblos ancestrales denominan "Buen Vivir" o "Vivir Bien”. Desde el punto de vista endógeno podrían considerarse las características de este modelo de desarrollo como adecuado a la resistencia y lucha respecto de la modernidad venida desde el paradigma europeo. Tal expresión, eminentemente ancestral, podría compararse, como además se lo ha hecho, con el Socialismo, modelo alternativo frente al Capitalismo resultante de la Modernidad.

Sin embargo, el socialismo, no es más que una palabra siguiendo análogamente a Pierre Bourdieu (2002) quien utilizaba tal expresión para referirse a la juventud. Por supuesto, si hay una utopía de por medio (socialismo, comunitarismo, humanismo, Buen Vivir, reino de Dios, etc.), es porque hay un sistema que desde el error y la injusticia permite ver nuevos horizontes. Eso es el capitalismo, caracterizado por su afán de lucro, por generar ganancia y excedentes que permitan el enriquecimiento individual, obviando cualquier valor que se interponga en ese camino, y haciendo visible el nuevo espíritu de la época "hacerse rico, olvidarse de todos, menos de uno mismo". (Chomsky, 2005). Por ello se trata de un sistema que se apropia del trabajo y genera 


\section{Siwô’' Volumen 7, número 2, año 2013}

explotación y subordinación de todos los aspectos de la vida.

El capitalismo divide a la sociedad en clases catalogando a unos como ricos y a otros como pobres y dejando en claro que ese es el status quo del que no se puede salir. Ese es el punto de partida para separar lo político de lo civil haciendo patente que el poder se lo lleva desde pocas manos y que la población solo debe obedecer. Este poder es capaz de monopolizar la represión, la economía y la legitimidad, apoyado además por los sistemas institucionales (iglesia, escuela) que ideológicamente venden la idea de que los ricos lo son por bendecidos y los pobres por vagos, y manteniendo a ultranza la sociedad en estado colonial.

Hay por lo tanto un endiosamiento del lucro, que expresa que "hay que tener éxito, hay que tener dinero", y que se opone a toda visión comunitaria, de la diversidad, e incluso que pretenda defender a la naturaleza para la que solo puede haber una actitud depredadora. El capitalismo cosifica o reifica (Honneth, 2007) tanto a la naturaleza como al ser humano volviéndolos mercancía y con mucho menos valor que las cosas insignificantes. En medio de esta perspectiva no puede haber espacio para nada que transforme estos valores, por lo cual, incluso Dios, como categoría sagrada es cosificado ${ }^{2}$.

Los pueblos de América Latina y muchos otros lugares de resistencia que han acogido las reflexiones por ejemplo de los Foros Sociales Mundiales, buscan elaborar una visión alternativa al capitalismo. Incluso naciones como Ecuador, Bolivia o Venezuela, han incluido nuevos principios en sus constituciones como garantía e inicio de la búsqueda de aquello que los pueblos originarios denominan "Vivir bien" o "Buen vivir".

Esta utopía de diversidad de nombres, y palabras que lo definen, puede sintetizarse en las siguientes características:

1. A nivel económico, la producción ya no tiene como objetivo el lucro por el lucro, se produce para satisfacer necesidades, y por lo tanto no hay explotación sino desarrollo comunitario, y desarrollo de la individualidad en beneficio de lo comunitario. El valor de uso se coloca por encima del valor de cambio y desde esta perspectiva, cambian los

\footnotetext{
2 Se puede ampliar el tema en un ensayo personal titulado "El Dios Cosificado" (Calderón, 2013), en: https://hypomnemata.jux.com/1067298
} 


\section{Siwô' Volumen 7, número 2, año 2013}

patrones del desarrollo, y la ciencia se pone al servicio de la humanidad.

2. A nivel político, se fusiona la sociedad política con la sociedad civil, y hay una clara conciencia de que el poder se encuentra en quienes lo otorgan, es decir el pueblo. Surge una democracia comunitaria, en la que el papel del Estado es el de convertirse en gestor de lo público.

3. A nivel social desaparecen las clases; los derechos son pensados para todos, sin discriminación; se reconoce, valora y usa el aporte de los pueblos al Estado y a otros pueblos, entre quienes no hay jerarquías. Además la toma de decisiones se socializa cada vez más, siendo participes de ellas, toda la sociedad.

4. A nivel ético se defiende y promueve el respeto supremo a la vida y la naturaleza en la que están incluidos los seres humanos, hay un fuerte apego a la comunidad de la que se forma parte y por ello se desarrollan la solidaridad y el trabajo en equipo, sin olvidar la dimensión individual de cada ser humano.

Resulta evidente y por ende lamentable que toda esta visión que abre a la utopía y otorga un horizonte de esperanza, ha sido muchas veces maquillada y saboteada por aquellas naciones que, desde el supuesto interés por el "desarrollo", impiden que realmente exista tal.

La realización de este horizonte depende no solo de algunos gobiernos que trabajan en esta línea, sino de la lucha misma llevada a cabo por las clases desfavorecidas, por los intelectuales, por los jóvenes, por todos. La revolución tiene que irradiarse, y en ello el pueblo latinoamericano está dando verdaderas lecciones al mundo.

Sin embargo el camino utópico pasa por el ser humano que es quien debe promover la lucha, y por lo tanto pasa también por una nueva visión de humanidad en relación con el universo del cual se forma parte. Se hace necesaria la recuperación de la identidad, la espiritualidad y la filosofía; la posibilidad de amar, de ser amados; de vivir plenamente; de saber dormir, respirar, escuchar; de recuperar el pensamiento y también el sentimiento; en fin, de retornar al equilibrio, al Pachakutik, para entonces comenzar a Vivir Bien. 


\section{Siwô' Volumen 7, número 2, año 2013}

\section{Conclusión}

Frente a la existencia de dos matrices civilizatorias se requiere de diálogo que permita procesos transmudarnos y que culminen en el acercamiento al paradigma del Buen Vivir y a la Epistemología del Sur. Este camino ha de pasar por el reconocimiento de los propios saberes y concepciones, la lucha por la consecución de objetivos comunes, la mirada planetaria, y la ciencia que apunte al desarrollo endógeno y la complejidad. Ahora bien, el primer paso para ello es "pensar" y "pensarnos" fuera del estado colonial, como bien plantea De Sousa (2009:108): "La profundización de la comprensión de las relaciones de poder y la radicalización de la lucha contra ellas pasa por la imaginación de los dominados como seres libres de dominación".

Esto si bien podría comprenderse como un mero ejercicio de sugestión, no lo es tal ya que produce mundos y al producirlos permite que las utopías se vayan volviendo realidad aunque tal concepto anule dicha posibilidad. Siguiendo a Fernando Birrí, citado por Galeano, la Utopía está en el horizonte y sirve para caminar. En este caso la concreción de una matriz civilizatoria propia que pueda estar en permanente construcción puede asemejarse a tal horizonte que con cada paso permite un avance hacia la tan necesaria Utopía. El Buen Vivir será en la medida en que existan procesos de liberación que atraviesen por opciones radicales frente a estructuras injustas, y que al mismo tiempo renueven el pensamiento y el sentimiento en una total expresión de descolonialidad.

La lucha desde los pueblos ancestrales, desde las bases, desde los grupos organizados será indispensable para tal fin, y por ello, hay que fundamentar las opciones desde nuevas miradas de la cultura, del pensamiento, de la ciencia, del desarrollo y de la vida. Se ha buscado analizar las concepciones existentes en Abya Yala para desde allí manifestar que es posible ir construyendo, desde el diálogo, tales visiones desde lo endógeno, revalorizando los saberes y construyendo con ellos la matriz civilizatoria ancestral contemporánea y contextualizada. 


\section{Siwô’ Volumen 7, número 2, año 2013}

\section{Referencias bibliográficas}

Apel, K. Dussel, E. Fornet, B. Fundamentación de la ética y filosofía de la liberación. México: Siglo XXI, 1992. Impreso.

Argueta, A. "El diálogo de saberes, una utopía realista". En Saberes Colectivos y diálogo de saberes en México. Cuernavaca: UNAM, CRIM; Puebla, Universidad Iberoamericana (2011), p.495-510. Impreso.

Bourdieu, P. "La juventud no es más que una palabra”. En Sociología y Cultura. México: Grijalvo (2002), p. 163-173. Impreso.

Chomsky, N. Sobre democracia y educación. Volumen I. Escrito sobre ciencia y antropología del entorno cultural. Barcelona: Paidós, 2005. Impreso.

Delgado, F. "Transdisciplinariedad y diálogo intercientífico como nuevos paradigmas de las ciencias”. Ed. Delgado, F., y Rist, S. La Transdisciplinariedad y la Investigación participativa revalorizadora en una perspectiva de diálogo de saberes e intercientífico. Cochabamba: AGRUCO/ UMSS-CDE NCCR, 2013. Impreso.

Delgado, F. Escobar, C. "El diálogo intra, intercultural e intercientífico en el contexto global y latinoamericano para un desarrollo endógeno sostenible”. Ed. Delgado, F. Escobar, C. Diálogo intercultural e intercientífico. Serie cosmovisión y ciencias $\mathrm{N}^{\circ}$ 2. La Paz: AGRUCO/UMSS COMPAS. PLURAL Editores, 2006, p.15-30. Impreso.

Derrida, J. De la gramatología. Buenos Aires: Editorial Siglo XXI, 1997. Impreso.

De Sousa, B. Una epistemología del sur. México D.F: Siglo XXI, 2009. Impreso.

Dussel, E. "Europa, modernidad y eurocentrismo". Ed. Lander Edgardo. La colonialidad del saber: eurocentrismo y ciencias sociales. Perspectivas latinoamericanas. Buenos Aires: CLACSO, 2000, p.41-53. Impreso.

Galeano, E. Ser como ellos y otros artículos. México: Siglo XXI, 1992. Impreso.

Galeano, E. Patas Arriba, la escuela del mundo al revés. Madrid: Siglo XXI, 2004. Impreso. 


\section{Siwô’' Volumen 7, número 2, año 2013}

Gallazzi, S. Por una tierra sin mar, sin templo, sin lágrimas y llena de esperanza. Introducción a una lectura militante de la Biblia. Córdova: Tiempo Latinoamericano, 1995. Impreso.

Geertz, C. La interpretación de las culturas. Madrid: Gedisa, 1988. Impreso.

Haverkort, B. Delgado, F. Shankar, D. Millar, D. Hacia el diálogo intercientífico. Construyendo desde la pluralidad de visiones de mundo, valores y métodos en diferentes comunidades de conocimiento. La Paz: Plural, 2013. Impreso.

Heidegger, M. El ser y el tiempo. México: Fondo de Cultura Económica, 2007. Impreso.

Hinkelammert, F. La Fe de Abraham y el Edipo occidental. San José, Costa Rica: DEI, 1988. Impreso.

Honneth, A. Reificación. Madrid: Katz, 2007. Impreso.

Krotz, E. La otredad cultural, entre utopía y ciencia: un estudio sobre el origen, el desarrollo, y la reorientación a la antropología. Madrid: Fondo de Cultura Económica, 2002. Impreso.

Lazlo, E. Una visión del mundo holística para una civilización planetaria. En Haverkort et al. Moviendo visiones de mundo. Reformando ciencias, políticas y prácticas para el desarrollo endógeno sustentable. Serie Cosmovisión y ciencias número 5. La Paz: Plural, 2007. Impreso.

Levinas, E. Humanismo del otro hombre. Madrid: Caparrós, 1993. Impreso.

Nietzsche, F. La genealogía de la moral. Madrid: Alianza Editorial, 2006. Impreso.

Payne, M. Diccionario de teoría crítica y estudios culturales. Buenos Aires: Paidós, 2008. Impreso.

Schökel, L. La Biblia de Nuestro Pueblo. Bilbao: Mensajero, 2009. Impreso.

\section{Vídeos}

“Álvaro García Linera. Socialismo Comunitario. Vicepresidente de Bolivia”. You Tube. Recuperado de: http://youtu.be/bjMw8LuWldg

"Marta Harnecker en el foro internacional Los nuevos retos de América Latina: socialismo y Sumak Kawsay: Socialismo del siglo 21". You Tube. Recuperado de: http://www.youtube.com/watch?v=4A-NjxX_oOo 


\section{Siwô’' Volumen 7, número 2, año 2013}

"David Choquehuanca. Reflexión sobre el Vivir Bien". You Tube. Recuperado de:

Parte-1: http://youtu.be/3_ZGxLM2RDw

Parte-2: http://youtu.be/2o6uTU9oUNA

Parte-3: http://youtu.be/qEFNuM-cEk0

"Boaventura de Sousa Santos: Relación entre ciencia (occidental) y los saberes populares". You Tube.

Recuperado de: http://www.youtube.com/watch?v=cN3ZXd5zjoQ

"Edgar Morin: Pensamiento complejo. Resumen de su pensamiento". You Tube Recuperado de: http://www.youtube.com/watch?v=zwEoR8aVZFg

y en voz original: http://www.youtube.com/watch?v=ZNrNg8YzCAk

"Enrique Dussel en el Seminario de Razón y Revolución”. You Tube. Recuperado de: http://www.youtube.com/watch?v=K3P8f1bBqmg

"Leonardo Boff: Teología de la Liberación y Ecología". You Tube. Recuperado de: http://www.youtube.com/watch?v=g8k78XsXBKs

“Orlando Fals Borda: Desarrollo Endógeno Suramericano” You Tube. Recuperado de:

Parte-1: http://www.youtube.com/watch?v=pyt1XtlWjSw

Parte-2: http://www.youtube.com/watch?v=7b0g2VNRui8

Parte-3: http://youtu.be/r3siqvUMwNU

Parte-4: http://youtu.be/_uNMa5du8FI 